Analytica Chimica Acta, 141 (1982) 57-64

Elsevier Scientific Publishing Company, Amsterdam - Printed in The Netherlands

\title{
RESPONSE PROPERTIES, APPLICATIONS AND LIMITATIONS OF CARBONATE-SELECTIVE POLYMER MEMBRANE ELECTRODES
}

\author{
JULIE A. GREENBERG and M. E. MEYERHOFF* \\ Department of Chemistry, The University of Michigan, Ann Arbor, $M I 14109$ (U.S.A.)
}

(Received 23rd March 1952)

\section{SUMMARY}

The preparation and response characteristics of a carbonate-selective polymer membrane electrode are reported. The electrode is prepared by incorporating Aliquat 336, trifluoroacetyl-p-butylbenzene and di-2-ethylhexyl sebacate or dioctyl phthalate in a poly(vinylchloride) membrane matrix. The effect of membrane composition and electrode response in various buffer systems are examined. Under buffer conditions appropriate for practical measurements, potentiometric data yield the following selectivity pattern: $\mathrm{ClO}_{-}^{-}=$salicylate $>$total carbon dioxide species $>\mathrm{I}^{-}>\mathrm{NO}_{3}^{-}>$acetate $>$ $\mathrm{Cl}^{-}>\mathrm{Br}^{-}$. The electrode can be readily fabricated in tubular form and utilized within a very simple flow-injection arrangement to determine total carbon dioxide species. The possible applications of the electrode to serum $\mathrm{CO}_{2}$ measurements as well as within newly devised gas-sensing arrangements for dissolved $\mathrm{CO}_{2}$ are also examined.

The accurate and rapid determination of total carbon dioxide species (e.g., $\mathrm{CO}_{2}$, hydrogencarbonate, and carbonate) in physiological, industrial, and environmental samples presents a formidable challenge. At present. total $\mathrm{CO}_{2}$ is most often determined with a Severinghaus-type potentiometric gas sensor [1] after the sample has been acidified to $\mathrm{pH}<5.5$. In such systems, measurements are based on the diffusion of $\mathrm{CO}_{2}$ through a silicone rubber membrane into a thin film of hydrogencarbonate solution in contact with a glass pH electrode. A change in pII results within the aqueous film as complete equilibration of the gas across the membrane is achieved. While widely employed, the Severinghaus design suffers from limitations because of its slow response times, the fragile and costly nature of the required flatbottom $\mathrm{pH}$ glass electrode, and the large response of the sensor to volatile as well as some less volatile organic acids [2].

In view of these limitations, there have been numerous attempts to prepare alternative potentiometric devices capable of detecting total $\mathrm{CO}_{2}$ species in solution. These devices include membranes based on solid ion-exchange resins sensitive to hydrogencarbonate [3] and pseudo "bicarbonate"-responsive electrodes based on dual $\mathrm{pH}$ sensitive $/ \mathrm{CO}_{2}$ permeable polymer membranes $[4,5]$. The former lacked selectivity while the latter were really gas-sensing electrodes in which response to hydrogencarbonate occurred as equilibrium levels of $\mathrm{CO}_{2}$ (in the hydrogencarbonate solutions) permeated a polymeric 
pH-responsive membrane, altering the internal membrane potential of the sensor (i.e., changed $\mathrm{pH}$ at the internal surface of the membrane). Another "bicarbonate" electrode, based on a liquid membrane with a fluorinated ketone anion-exchanger was patented by Corning [6]. It was subsequently demonstrated by Herman and Rechnitz $[7,8]$ that this electrode (utilizing Aliquat 336 in trifluoroacetyl-p-butylbenzene as the active membrane phase) was really selective for carbonate, not hydrogencarbonate. Indeed, these workers were able to use this liquid membrane probe to determine total $\mathrm{CO}_{2}$ in blood by measuring equilibrium amounts of carbonate at $\mathrm{pH} 8.4$ [9] Kodak Corporation now utilizes a polymer form of this membrane to measure serum $\mathrm{CO}_{2}$ within their new Ektachem clinical analyzer [10], but no literature report has appeared describing the preparation and properties of such a membrane.

The purpose of this paper is to report our findings on the preparation, optimization, and response characteristics of a carbonate-selective polymeric membrane electrode. In addition, a novel tubular form of the electrode is described and utilized in a simple flow-injection arrangement for the determination of total $\mathrm{CO}_{2}$. Limitations on the use of this membrane electrode system for direct blood $\mathrm{CO}_{2}$ measurements are discussed. Finally, the concept of incorporating this polymer membrane electrode within a newly devised gas-sensing arrangement, highly selective for $\mathrm{CO}_{2}$, is also examined.

\section{EXPERIMENTAL}

\section{Apparatus}

All static and flow-injection potentiometric measurements were made with a Coming Model $12 \mathrm{pH} / \mathrm{mV}$ meter used in conjunction with a HeathSchlumberger Model 204 strip-chart recorder. All measurements were made vs. a saturated calomel reference electrode at room temperature. An Orion Model 92-00 liquid-membrane electrode body was used to evaluate the static response of carbonate-selective polymer membranes.

A schematic diagram of the carbonate electrode-based flow-injection system is shown in Fig. 1. The system consists of a Rainin-Rabbit peristaltic

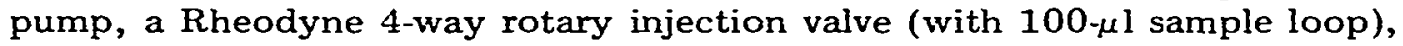
$50 \mathrm{~cm}$ of $1.14-\mathrm{mm}$ i.d. polyethylene tubing coiled in 1-inch loops, and a tubular carbonate polymer membrane electrode.

\section{Reagents}

All chemicals were of the purest grade available. Standard solutions and reagent buffers were prepared with distilled-deionized water. Most experiments were carried out with either a $0.05 \mathrm{M}$ or $0.10 \mathrm{M}$ tris-(hydroxymethyl)aminomethane-hydrogen sulfate $\left(\right.$ Tris- $\mathrm{SO}_{4}$ ) buffer, $\mathrm{pH} 8.75$, as the sample or diluent reagent.

Trifluoroacetyl-p-butylbenzene (TFBB) was synthesized as described previously [8]. Aliquat 336 (tricaprylylmethylammonium chloride) was 


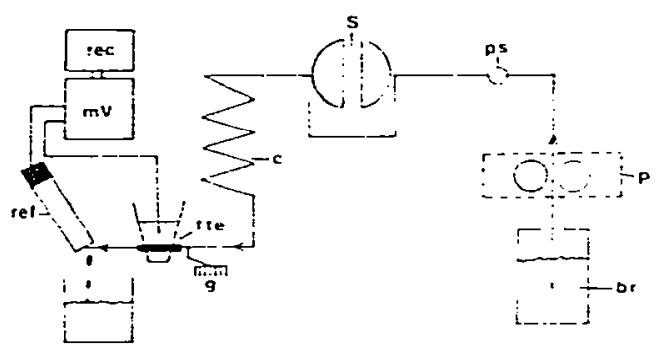

Fig. 1. Schematic diagram of the polymer carbonate electrode-based now-injection system: (fte) tubular flow-through carbonate electrode; (g) electrical ground; (c) coiled polyethylene tubing; (s) sample injection valve; (ps) pulse suppressor; (p) peristaltic pump; (br) buffer reservoir.

obtained from Aldrich Chemical Co. Dioctyl phthalate and dioctyl sebacate were Kodak products, while di-2-ethylhexyl sebacate was obtained from ICN Pharmaceuticals.

\section{Preparation and evaluation of membrane electrodes and gas sensor}

For static electrode studies, the carbonate-selective membrane was prepared as follows. Poly (vinylchloride) $(55 \mathrm{mg})$, plasticizer $(50 \mu \mathrm{l}), \operatorname{TFBB}(50 \mu \mathrm{l})$ and THF (1 ml) were mixed thoroughly and the resulting solution was poured into a glass ring (1-inch diameter) placed on top of a glass slide. After the solvent had evaporated, the membrane was peeled from the slide and smaller round discs were cut out $(3-\mathrm{mm}$ diameter). Such a piece was placed in the end of an Orion liquid electrode body and secured in place by tightening the outer cap. The electrode was filled with an internal solution of $0.01 \mathrm{M}$ $\mathrm{NaHCO}_{3}-0.01 \mathrm{M} \mathrm{NaCl}$ before testing.

For evaluation within the gas sensor arrangement, a small piece of the above membrane was affixed to the end of a plastic pipet--tygon tubing assembly as described previously for an ammonium-selective membrane $[11,12]$. The rest of the gas sensor was also assembled in an analogous manner to the earlier ammonia probe [12] except that a silicone rubber membrane was used as the outer gas-permeable material.

A tubular flow-through carbonate electrode was prepared with a slightly different membrane composition. Instead of $55 \mathrm{mg}$ of PVC, $25 \mathrm{mg}$ was used in the casting solution. The electrode was made in a $0.89-\mathrm{mm}$ i.d. piece of tygon tubing by methods recently described for tubular ammonium electrodes [13]. The electrode was encased in an appropriate housing into which the internal reference solution $(0.01 \mathrm{M} \mathrm{NaHCO}-0.01 \mathrm{M} \mathrm{NaCl}$ ) and a $\mathrm{Ag} / \mathrm{AgCl}$ reference wire were placed.

The static electrode potentiometric response and selectivity characteristics were evaluated by making standard additions of $0.1 \mathrm{M} \mathrm{NaHCO}_{3}$, or interferents, to $25 \mathrm{ml}$ of well stirred Tris-- $\mathrm{SO}_{4}$ buffer. The $\mathrm{pH}$ of the buffer was simultaneously monitored with a glass electrode to determine whether 
responses observed were a result of $\mathrm{pH}$ changes caused by the addition of test reagents (a $\mathrm{pH}$ change shifts the $\mathrm{CO}_{3}^{2-} / \mathrm{HCO}_{3}^{-}$equilibrium and the electrode responds to $\mathrm{OH}^{-}$). For evaluation of the gas sensor, $\mathrm{CO}_{2}$ was formed by standard addition of $\mathrm{NaHCO}_{3}$ to a $0.2 \mathrm{M}$ citrate buffer, $\mathrm{pH} 4.50$.

\section{RESULTS AND DISCUSSION}

In preliminary efforts to utilize the liquid-membrane components described by Herman and Rechnitz [7] within a polymer matrix, it was found that TFBB was not a suitable plasticizer for PVC type membranes. Consequently, a mixture of that solvent along with more traditional plasticizers must be used in order to make functioning electrodes. Several plasticizers were tested and the response properties of the electrode were found to vary somewhat, depending on the plasticizer utilized. In general, these effects were not dramatic; however, optimal response with regard to slope was obtained with di-2-ethylhexyl sebacate and dioctyl phthalate. The ratio of plasticizer to solvent-exchanger, and the amount of PVC within the membrane were also studied. Again, no significant trend was observed, although a membrane composed of $23 \%$ plasticizer, $23 \%-4 \%$ Aliquat 336 in TFBB and $54 \%$ PVC consistently yielded optimal response.

\section{Characteristics of the electrode}

A considerable effort was made to determine the best buffer composition to use for practical evaluation of the electrode. Herman and Rechnitz [9] reported the use of a Tris-HCl buffer, $\mathrm{pH} 8.40$, for automated serum $\mathrm{CO}_{2}$ measurements using a liquid-membrane carbonate electrode. For the polymer membrane electrode, several buffer systems (e.g., Tris, 2-amino-2-methyl-1,3propane-diol, 2-amino-2-methyl-1-propanol) were studied to find the one which yielded optimal response to total $\mathrm{CO}_{2}$ species. In addition, the counter-ion was varied within the buffers. For example, Fig. 2 shows the response of the static carbonate polymer electrode to total carbonatehydrogencarbonate species in a series of $0.05 \mathrm{M}$ Tris-X buffers, all at pH 9.0. It can be seen that Tris- $\mathrm{SO}_{4}$ offers the widest dynamic range and the best slope (typically $25-27 \mathrm{mV} /$ decade). Clearly, the data from this study reflect the innate selectivity of the membrane with respect to various buffer anions. After it had been shown that Tris- $\mathrm{SO}_{4}$ was the most useful working buffer for quantitative purposes, a more complete selectivity study was done with this buffer solution as a constant background. Figure 3 shows the response of the carbonate electrode to total $\mathrm{CO}_{2}$ species (i.e., carbonate and hydrogencarbonate) and to other anions in $0.1 \mathrm{M}$ Tris- $\mathrm{SO}_{4}, \mathrm{pH} 8.75$. It can be seen that the electrode responds logarithmically to total $\mathrm{CO}_{2}$ species between $7 \times 10^{-4}$ and $1 \times 10^{-2} \mathrm{M}$, although useful response is observed to $10^{-4} \mathrm{M}$. It should be realized that at $\mathrm{pH} 8.75$, only $2.4 \%$ of the total $\mathrm{CO}_{2}$ species is carbonate and thus the membrane is far more selective for carbonate than it appears from Fig. 3. However, because the electrode also has a large Nemstian 

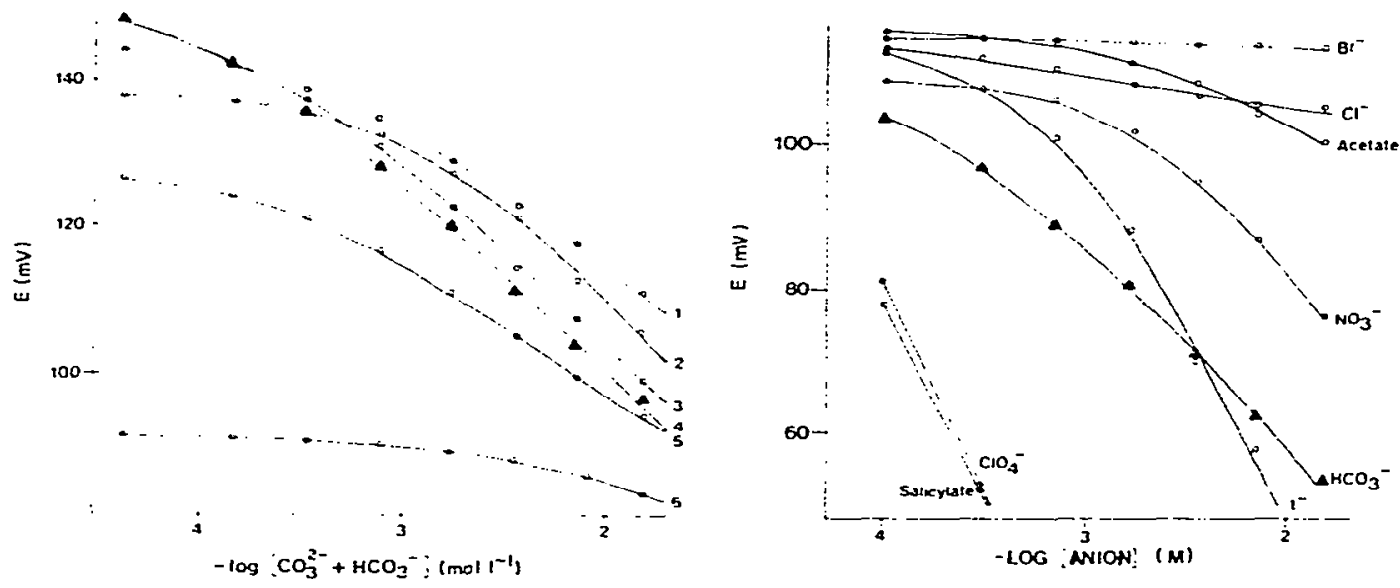

Fig. 2. Response of static carbonate polymer-membrane electrode to total $\mathrm{CO}_{2}$ (predominately carbonate and hydrogencarbonate) in various $0.05 \mathrm{M}$ Tris-X buffers, $\mathrm{pH} 9.0$ : (1) Tris- $\mathrm{HCl}$; (2) Tris-citric acid; (3) Tris- $\mathrm{HBr}$; (4) Tris- $\mathrm{H}_{2} \mathrm{SO}_{4} ;(5)$ Tris- $\mathrm{HF}$; (6) Tris-HI.

Fig. 3. Potentiometric response of polymer carbonate electrode to various anions in a background of $0.1 \mathrm{M}$ Tris- $\mathrm{SO}_{4}, \mathrm{pH} 8.75$.

response to hydroxide ion, increasing the working $\mathrm{pH}$ would result in poorer detection limits toward total $\mathrm{CO}_{2}$ species. Indeed, $\mathrm{pH} \mathrm{S.75}$ was found to be a good compromise for practical measurement purposes and, therefore, Fig. 3 reflects the practical selectivity relative to total $\mathrm{CO}_{2}$ measurements (not relative only to carbonate). Figure 3 indicates that perchlorate and salicylate are the major interferences and that the selectivity order of the electrode is as follows: salicylate $=$ perchlorate $>$ total $\mathrm{CO}_{2}$ species $\geqslant \mathrm{I}^{-}>\mathrm{NO}_{3}^{-}>$ acetate $>\mathrm{Cl}^{-}>\mathrm{Br}^{-}$.

For the data shown in Figs. 2 and 3, a $0.01 \mathrm{M} \mathrm{NaHCO}_{3}-0.01 \mathrm{M} \mathrm{NaCl}$ solution was used as the internal reference solution. Response times were typically $20 \mathrm{~s}-1 \mathrm{~min}$ for complete equilibration. The effect of using buffered internal reference solutions was examined with the aim of avoiding any effect that $\mathrm{CO}_{2}$ diffusion through the PVC membrane $[4,5]$ might have on the equilibration time and slope of the electrode (e.g., $\mathrm{CO}_{2}$ diffusion could alter the $\mathrm{pH}$ of the internal solution and continuously change the $E^{\circ}$ of the electrode). The following buffers, all containing $10^{-2} \mathrm{M} \mathrm{NaCl}$, were evaluated: $0.1 \mathrm{M}$ Tris$\mathrm{SO}_{4}, \mathrm{pH} 8.75 ; 0.1 \mathrm{M}$ phosphate, $\mathrm{pH} 7.00 ; 0.1 \mathrm{M}$ citrate, $\mathrm{pH} 5.50$. Although shifts in the initial potentials were observed, the electrode performance for all of these internal buffers was essentially the same as when the unbuffered internal solution was used. This suggests that free $\mathrm{CO}_{2}$ gas levels are so low when the sample solution is at $\mathrm{pH} 8.75$ (0.4\% of total $\mathrm{CO}_{2}$ species), that no concern need be given to the $\mathrm{CO}_{2}$ diffusion problem, at least in the $10^{-4}-10^{-2} \mathrm{M}$ total $\mathrm{CO}_{2}$ working range. 


\section{Flow-injection system}

In an effort to utilize the electrode for rapid and accurate total $\mathrm{CO}_{2}$ determinations, it was judged desirable to incorporate the polymer membrane electrode into a flow-injection system. When a novel tubular electrode assembly [14] was used with a flow-injection system (Fig. 1) and a $0.1 \mathrm{M}$ Tris- $\mathrm{SO}_{;}(\mathrm{pH} 8.75)$ diluent stream, the potentiometric recording shown in Fig. 4 was obtained. These data were recorded by injecting $\mathrm{NaHCO}_{3}$ standards from the $100 \mu 1$ injection value. Typically, 40-50 samples per hour can be handled with good reproducibility $(\leqslant \pm 0.8 \mathrm{mV})$. In this flowing system, the electrode had a slightly lower slope, typically $23-25 \mathrm{mV} /$ decade between $5 \times 10^{-3}$ and $1 \times 10^{-1} \mathrm{M}$ total $\mathrm{CO}_{2}$ species. The shift in calibration plots when compared to Figs. 2 and 3 reflects the internal dilution factor within the flow-injection system. In this regard, because exact $\mathrm{pH}$ adjustment of the sample is critical for accurate total $\mathrm{CO}_{2}$ measurements, greater dilution within the system is required (achieved by using tubing of wider diameter and greater length).

In attempts to utilize the above flow-injection system for serum $\mathrm{CO}_{2}$ measurements, it was found that large positive errors resulted (using preassayed commercial control serum). This was apparently due to the presence of salicylate anions in the control serum (at $3.65 \times 10^{-4} \mathrm{M}$ [15]). Normal salicylate levels in blood are typically less than $1.0 \times 10^{-4} \mathrm{M}[16]$, but therapeutic levels for aspirin users are approximately $1.5 \times 10^{-3} \mathrm{M}$ [16] It is clear from Fig. 3 that any salicylate greater than normal levels will cause substantial positive errors in total $\mathrm{CO}_{2}$ measurements via the polymer carbonate electrode-based methods. The carbonate-responsive polymer membrane utilized by Kodak Corporation in their new instrument must also suffer salicylate response, because a recent patent [17] describes a buffer overcoat layer which is supposed to eliminate organic anion interferences.

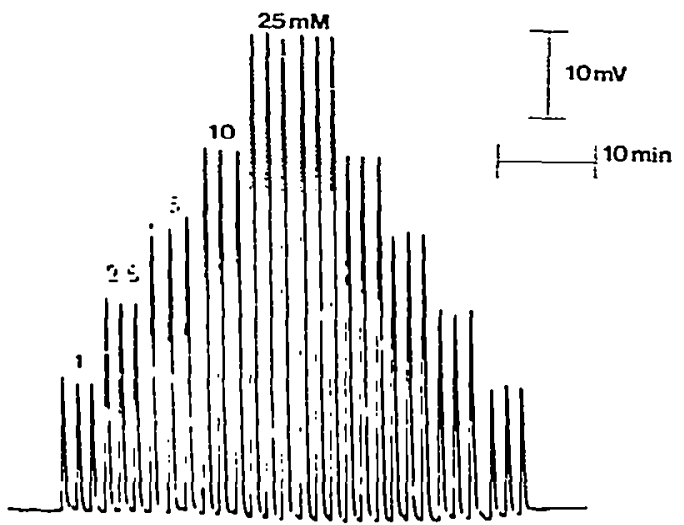

Fig. 4. Typical strip-chart recording and reproducibility obtained with carbonate electrodebased flow-injection system. Carrier flow rate, $2.0 \mathrm{ml} \mathrm{min} \mathrm{m}^{-1} ; 100-\mu 1$ injections. 
Because the Kodak system involves a single use, disposable, static membrane electrode arrangement, such a solution to this problem is feasible. However, such an approach could not be utilized in a flowing arrangement in which the membrane electrode is continuously being reused.

To improve the selectivity of the static carbonate polymer membrane, the feasibility of utilizing the electrode as an internal sensing element in a conventional total $\mathrm{CO}_{2}$ gas sensing arrangement was examined. The concept of using polymer electrodes as inner sensing elements was recently introduced via a new ammonia sensor [11]. Figure 5 illustrates the device used in this study. When a $0.1 \mathrm{M}$ Tris- $\mathrm{SO}_{4}$ buffer, $\mathrm{pH} 8.75$, served as the internal electrolyte, very small potentiometric responses were obtained as standard $\mathrm{NaHCO}_{3}$ was added to a sample solution of $\mathrm{pH} 4.50$. Indeed, for such an experiment, the predominant response was in the positive potential direction. This was because $\mathrm{CO}_{2}$ diffusion across the outer gas-permeable membrane caused a $\mathrm{pH}$ change within the thin film of buffer at the sensor tip. Such an effect is enhanced by the relatively large $\mathrm{pH}$ difference between the sample solution and the internal buffer solution (i.e., large buffer trap effect). When the internal buffer solution was replaced with stronger buffer solution, e.g., $0.5 \mathrm{M}$ Tris $\mathrm{SO}_{4}$, $\mathrm{pH}$ 8.75, the calibration plot shown in Fig. 6 was obtained. Response times were typically 2 min; however, the slope was lower than expected $(20 \mathrm{mV} /$ decade) and the logarithmic range was quite narrow. Again, at total $\mathrm{CO}_{2}$ levels greater than $10^{-3} \mathrm{M}$, the potentiometric response reverses because of a lowering of the $\mathrm{pH}$ in the buffer film (reduced carbonate ion levels in film). To overcome this problem, it would be desirable
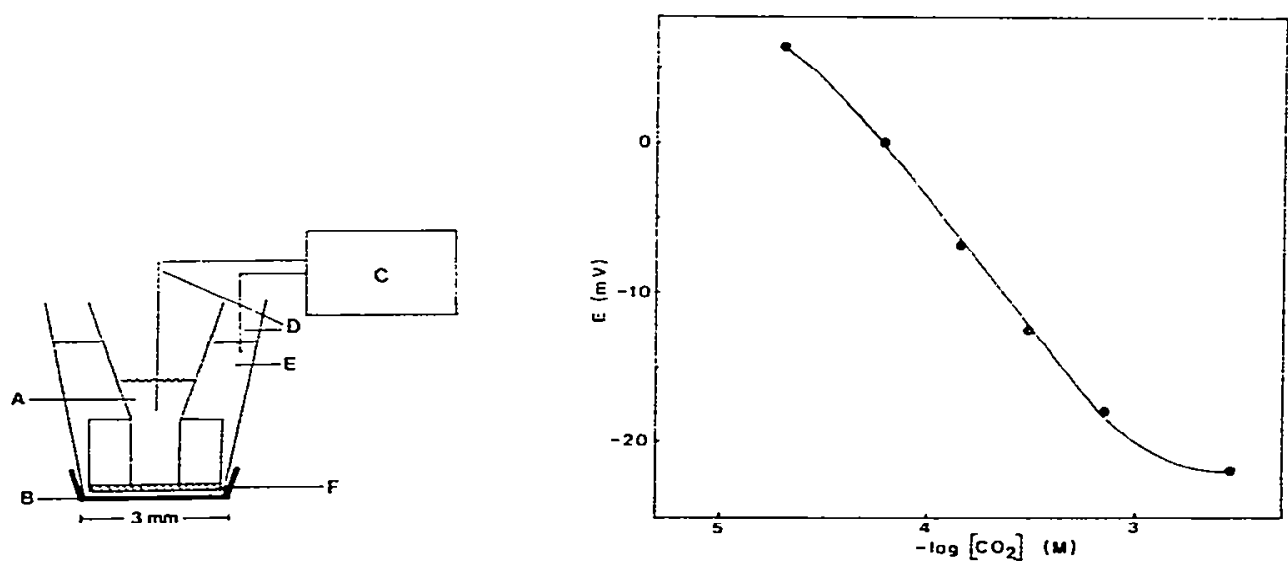

Fig. 5. Schematic diagram of polymer electrode-based carbon dioxide-responsive gas sensor: (A) $0.01 \mathrm{M} \mathrm{NaHCO}-0.01 \mathrm{NaCl}$ solution; (B) silicone rubber membrane; (C) $\mathrm{pH} / \mathrm{mV}$ meter; (D) Ag/AgCl electrodes; (E) Tris- $\mathrm{SO}_{4}$ buffer; (F) poly(vinylchloride) carbonate-selective membrane.

Fig. 6. Calibration curve for carbonate electrode-based potentiometric $\mathrm{CO}_{2}$ gas sensor. 
to utilize a hydrogencarbonate-responsive internal sensing element. This would allow the use of a lower $\mathrm{pH}$ internal buffer and thus would reduce the $\mathrm{pH}$ changes caused by the buffer trap effect. Work on this corcept is currently underway.

The authors acknowledge the laboratory work of Mr. Jeff Rosen and Mr. Leonidas Bachas in doing some of the experiments cited. This work was supported by the National Institutes of Health (Grant GM 28882-01).

\section{REFERENCES}

1 J. W. Severinghaus and A. F. Bradley, J. Appl. Phys., 13 (1958) 575.

2 R. K. Kobos, S. J. Parks and M. E. Meyerhoff, Anal. Chem., in press.

3 A. L. Grekovich, E. A. Materova and N. V. Garbuzova, Zh. Anal. Khim., 28 (1973) 1206.

4 L. W. Niedrach, U.S. Patent No. 3,898,147, August 5, 1975.

5 R. J. J. Funck, W. E. Morf, P. Schulthess, D. Ammann and W. Simon, Anal. Chem., 54 (1982) 423 .

6 W. M. Wise, U.S. Patent No. 3,723,281, March 27, 1973.

7 H. B. Herman and G. A. Rechnitz, Science, 184 (1974) 1074.

8 H. B. Herman and G. A. Rechnitz, Anal. Chim. Acta, 76 (1975) 155.

9 H. B. Herman and G. A. Rechnitz, Anal. Lett., 8 (1975) 147.

10 S. H. Kim, B. E. Babb, M. J. Bogdanowicz, J. C. Chang, D. S. Dancel, T. R. Kissel, M. W. Pipal, J. R. Sandifer, P. N. Schipelsky, R. Searle, R. W. Spayd and T. J. Steele, Clin. Chem., 26 (1980) 991.

11 M. E. Meverhoff, Anal. Chem., 52 (1980) 1532.

12 M. E. Meyerhoff and R. H. Robins, Anal. Chem., 52 (1980) 2383.

13 Y. M. Fraticelli and M. E. Meyerhoff, Anal. Chem., 53 (1981) 992.

14 M. E. Meyerhoff and Y. M. Fraticelli, Anal. Lett., 14 (1981) 415.

15 Data Sheet for Fisher Sera-Chem Control Serum, Lot no. 306-010, Fisher Scientific, Pittsburgh, PA, 1980.

16 R. B. Banke, in N. W. Tietz (Ed.), Fundamentals of Clinical Chemistry, W. B. Saunders, Philadelphia, 1976, Ch. 21.

17 S. A. Kim and H. J. Chang, U.S. Patent No. 4,272,328, June 9, 1981. 